\title{
GRACE, Climate Change and Future Needs: A Brief Review
}

Sandeep N Kundu*

Department of Geography, National University of Singapore, Singapore

*Corresponding author: Sandeep N Kundu, Department of Geography, National University of Singapore, Singapore, Tel: 09000633008; E-mail: geosnk@nus.edu.sg Received date: Oct 27, 2016; Accepted date: Nov 22, 2016; Published date: Nov 28, 2016

Copyright: (c) 2016 Sandeep NK. This is an open-access article distributed under the terms of the Creative Commons Attribution License, which permits unrestricted use, distribution, and reproduction in any medium, provided the original author and source are credited.

\begin{abstract}
Gravity Recovery and Climate Experiment (GRACE) is a satellite based observation of the Earth's gravitational field through time. Earth's gravitational field has long been studied to infer the densities of underlying rocks for geological characterization at various scales. Convention gravity measurements were done using spring gravimeters on ground. However continuous observations of temporal variations in the Earth's gravity field have become available at an unprecedented resolution of a few hundreds of kilometres through satellite based sensors. With the launch of GRACE in 2002, the study of the exchange of mass both within the Earth and at its surface in the short temporal interval has become possible. This has huge implications in studying the impacts of earth's surface processes involving the interaction of the atmosphere, hydrosphere, cryosphere and biosphere. GRACE gravity, therefore, has gained relevance for Earth scientists as an important tool to study the complex dynamics of the Earth system and climate change. The current article researches on the principles behind grave gravity variations and its applications to infer climate change and proposes the advances required to overcome the limitations of GRACE for climate change forecasting.
\end{abstract}

Keywords: GRACE; Gravity Field; Climate Change; Ocean mass; Land mass

\section{Introduction}

Newton's law of universal gravitation states that a particle attracts every other particle in the universe using a force that is directly proportional to the product of their masses and inversely proportional to the square of the distance between them. Denoted by g, the gravitational field strength is the acceleration that the Earth imparts to objects on or near its surface. This acceleration is measured in metres per second squared (in symbols, $\mathrm{m} / \mathrm{s}^{2}$ ) is a constant approximately 9.81 $\mathrm{m} / \mathrm{s}^{2}$. This constant is not uniform around the globe because it is a product of its mass distribution, variations in the density of the Earth's interior and undulating topography, thereby causing regional deviations to a scale of few tens of a millionth of $\mathrm{g}$. There are challenges in modelling these variations owing to the poor understanding of our Earth's structure and dynamic nature. Gravity Recovery and Climate Experiment (GRACE), provides a 9 day repeat data over the same region allowing the study of the gravity field's variations in the short temporal scale. As mass transport in the Earth's interior is a slow process, the variations in the short temporal scale can attributed to mass transport in the near surface with high relevance to hydrological processes, surface water changes and ground water [1].

The short temporal variations of the Earth gravity field are dominated by the mass exchange processes between the atmosphere, cryosphere, hydrosphere and biosphere. Climate patterns drive these interactions and therefore variations in mass distributions are a direct impact of climatic variations. Availability of GRACE gravity since 2002 facilitates the study of this variability at different temporal scales providing information on sub-annual to decadal variations interpretations of which provides insight on climatic changes.

Before the availability of GRACE, hydrological applications aimed at studying Total Water Storage (TWS) changes over land could only be done at local watershed scale. Moreover these could only focus on one component i.e., groundwater, soil moisture or surface water, instead of TWS. Gravity field variations and its correlation with precipitation and run-off at regional scale has realised the potential of GRACE in many environmental and climate change applications. The findings of such studies have influenced the water management policies of large countries for secure a sustainable land and water management practice. We discuss the principles behind GRACE data and its characteristics and how it has been used in various applications which infer climate change and finally propose the future requirements which could overcome the limitations of GRACE gravity data.

\section{About Grace}

\section{GRACE satellites}

GRACE consists of two satellites in a low, near circular, near-polar orbit with an inclination of $89^{\circ}$, at an altitude of about $500 \mathrm{~km}$, separated from each other by a distance of roughly $220 \mathrm{~km}$ alongtrack. The satellites have a repeat imaging over the same area once in 9 days and roughly a month of coverage data is needed to produces a seamless model for the globe (Figure 1)

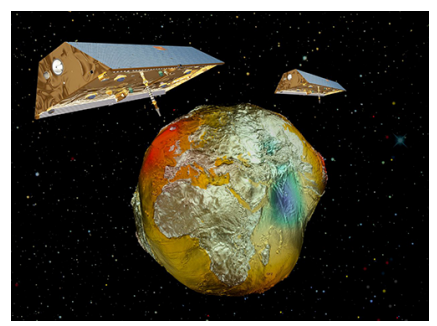

Figure 1: The twin satellites of GRACE with the earth's gravity field. 


\section{Gravity from GRACE}

The mission does not measure gravity directly with an active sensor, but is based on the satellite-to-satellite tracking concept, which tracks variations in the inter-satellite distance and its derivatives to recover gravitational information. As the two GRACE satellites are separated by a certain distance, and the gravitational pull of mass on the earth's surface is inversely proportional to the squared distance to each satellite, the orbit of each of the satellites will be perturbed slightly differently when it encounters a sizable dense mass on earth's surface. The leading satellite will be pulled slightly more toward the mass than the trailing one increasing the separation between the satellites. These minute changes-in the order of a few micrometres-can be measured by means of a dual-one way microwave ranging system (KBR). Other non-gravitational forces, such as atmospheric drag will also alter the relative distance, and are accounted for using on-board accelerometer measurements. Two star-cameras measure the orientation of these satellites in space. The satellites are equipped with Global Positioning System (GPS) receivers so that their location is known. Thus from the instantaneous orientation, ranging and GPS data (called the level-1 data), variations in the Earth's gravity field can be estimated. An iterative procedure involving a priori model of the Earth's mean gravity field is used in combination with other background force models (planetary interactions and tidal components) are used to determine the orbit of both satellites. The gravitational effects of ocean and atmosphere mass variations are removed from the measurements at this step using numerical models else their high-frequency contributions would influence the results [2].

\section{Noise Reduction and Smoothing}

The gravity field is sampled using the variations in the long-track distance between the two satellites, which circle the Earth in a nearpolar orbit. As a result, the observations bear a high sensitivity in the North-South direction, but little in the East-West direction. Errors in the instrument data, shortcomings in the background noise models and other processing errors results in unusual gravity gradients in the East-West direction. This results in stripes along the North-South direction [3]. Several methods have been developed to reduce the effect of this noise in the GRACE data which include spatial and frequency based smoothing methods (Figure 2). These methods reconcile the noise but unfortunately damp the geophysical signals thereby hindering a direct quantitative interpretation from GRACE observations.

The processed GRACE data products are then used to produce computations for land mass and ocean mass grids for integrated studies with other ground based information on climate. Most available as Monthly global $1^{\circ}$ grids. Different grids for land mass and ocean mass are available for research. A Global Land Data Assimilation System (GLDAS) has been developed jointly by scientists at the National Aeronautics and Space Administration (NASA) Goddard Space Flight Center (GSFC) and the National Oceanic and Atmospheric Administration (NOAA) National Centers for Environmental Prediction (NCEP), which makes use of new generation of ground and space based observation systems for land surface models aimed at supporting improved forecasting and hydrometeorological investigations [4].

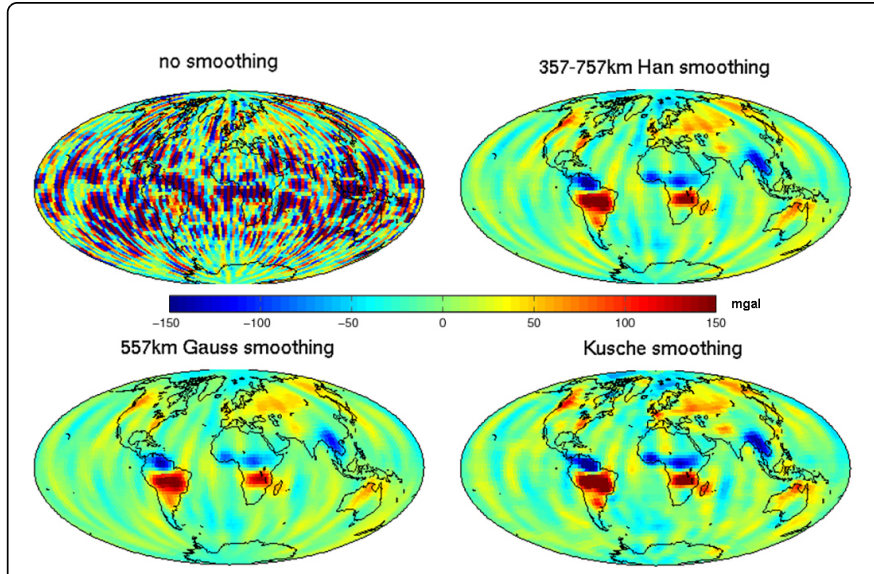

Figure 2: Results from different approaches to filtering stripe noise from GRACE data.

Mass Concentration blocks (Mascons) are another form of gravity field basis functions to which GRACE's inter-satellite ranging observations are fit, which supports the implementation of geophysical constraints [5]. Monthly grids for GLDAS, Mascon, Land mass and Ocean mass can be downloaded from GRACE Tellus server (ftp:// podaac-ftp.jpl.nasa.gov/allData/tellus/L3/).

\section{Grace and Climate Change}

Climate influences the distribution of mass on earth's surface in regular consistent patterns. Climate change disrupts these patterns which feedback in different forms like shifts in Earth's axis of rotation. Though gradual, a consistent shift over decades could drive further shifts in climate patterns that would add another level of complex mass distribution patterns. Climate change interpretations from GRACE are not direct and are purely based on mass transfer studies related to water and ice on land and oceans at a monthly temporal scale. The below are brief summaries of the different applications trending in literature which involves GRACE data for understanding our Earth's response from the changing climate in the last decade.

\section{Total Water Storage (TWS)}

Continental water storage and snow pack at high latitudes and their changes over time are reflected in the gravity field variations. Continental water storage is a key component of the terrestrial and global hydrological cycles, having an important control over water, energy and biogeochemical fluxes, thus playing a major role in the Earth's climate system [6]. However totals continental water storage remains completely unknown at regional and global scales because of the lack of direct hydrological measurements. GRACE satellite gravimetry offers a very interesting alternative remote sensing technique to measure changes in TWS (ice, snow, surface waters, soil moisture, and groundwater) over continental areas, representing a new source of information for hydrologists and global hydrological modellers [7].

Over a drainage basin, the water mass balance equation to solve is

$$
\frac{d W}{d t}=P-E-R
$$


Page 3 of 5

Where $\mathrm{dW} / \mathrm{dt}$ is the TWS variations that are directly provided by GRACE over the considered region [8]. If $\mathrm{P}$ (precipitation) is known and $\mathrm{R}$ (runoff) is modelled then variations in E (Evapotranspiration) can be estimated which essentially represents vertical water fluxes. GRACE TWS data with observed precipitation and stream flow Rodell et al. [4] can be used to identify patterns of changes which would be critical in forecasting drought episodes in a region. Several applications on large river basins have reflected the changes in seasonal changes in TWS [9-11] through integrated studies using field based data. Cazenave and Chen [12] calculated the rates of mass changes in water column equivalent for 2002-2009 (Figure 3). The observations included the loss of Ice sheet thickness in the Himalayas and increasing loss of water (ground water) around the New Delhi region attributed to excessive pumping of water by an population that have increases over the time period.

However there are several limitations to using GRACE gravity especially when the study requires separation of TWS into its hydrologic constituents without the help of field collected data. Integration of similar information through disparate temporal scales and precision results in complicated combination with other hydrologic products, all of which have their own limitations and errors. The differing spatial and temporal scales between GRACE (a global, monthly product) and in situ data such as river or well gauges (point-source measurements which are non-uniform in space and time) makes exact comparisons and combinations difficult.

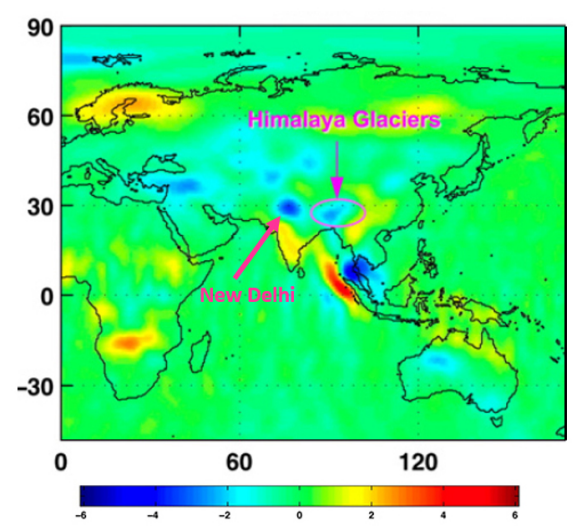

Figure 3: Global mass rate changes ( $\mathrm{cm} /$ year of equivalent water height rate) estimated from GRACE time-variable gravity data from period Sep 2002-Aug 2009. Modified from Cazenave and Chen [12].

\section{Ice Mass Balance}

A giant leap forward in our understanding of the cryosphere was made by the advent of satellite remote sensing. Despite the lack of missions specifically dedicated to observing the mass balance of the cryosphere, estimates of volume and mass changes were already made in the 1990s using satellite radar altimetry. GRACE has taken this forward by providing new insights on the mass balance of smaller ice caps and glacier systems. Direct observations of glaciers are sparse, both in space and in time, because of the labour intensive nature and tend to be biased toward glacier systems in accessible, mostly maritime, climate conditions. GRACE-derived mass balance estimates of Antarctica and Greenland (Figure 4) have been determined from the gravity fields of the GRACE project [13]. Mass changes of ice sheets have been resolved by using Mascons form various drainage basins.

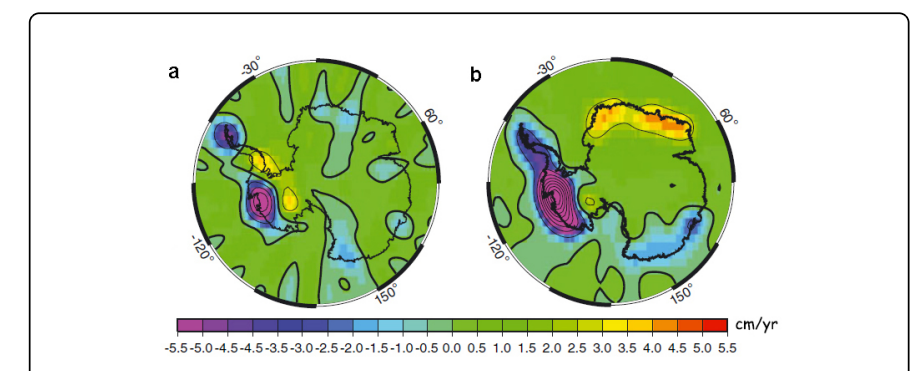

Figure 4: Antarctic ice mass changes a) Jan 2003 to Dec 2006) and b) Dec 2006 to Nov 2012. Sourced from Velicogna and Wahr [13].

Velicogna and Wahr [13] estimated an extreme decrease of ice mass of $-152 \pm 80 \mathrm{~km}^{3} /$ year for Antarctica. Although GRACE-based estimates are not corrected for long-term Post-Glacial Rebound (PGR), the mass balance of Antarctica appears to be close to zero. Uncertainties in such studies are primarily because of the inherent North-South striping noise and inaccurate modelling of PGR from GRACE data although it there has been reports of possibilities to reduce these from combination of different satellite based techniques and data. Studies have found that approximately $60 \%$ of the in situ glacier mass balance records are from the smaller European Alps, Scandinavia and north-western America.

Continuous and uninterrupted observation time series for very large glaciers were earlier unavailable, an issue which are overcome by GRACE, yet at the smaller spatial scale noise is larger required stringent validation of the results and interpretations.

\section{Ocean Water Distribution}

Ocean mass variations are important for diagnosing sea level budgets, the hydrological cycle, the global energy budget, and ocean circulation variability [14]. Seasonal cycles (Figure 5) and decadal trends of ocean mass at global and reginal scales could be determined from GRACE Release-05 data from which global flux of mass into the ocean approaches $2 \mathrm{~cm}$ per decade in equivalent sea level rise.

Historically, ocean mass variations, whether global or regional, have been difficult to diagnose although Bottom Pressure Recorders (BPRs) have been deployed in regional arrays for short term observations to investigate ocean boundary currents. Although ocean general circulation models have been used to study low-frequency ocean mass variability, results are often suspect owing to the time scale needed for deep ocean conditions to equilibrate.

Large negative trends south of Greenland and north of the West Antarctic Peninsula are likely owing to large ice mass loss signals leaking into the ocean even after attempting to correct with estimates based on GRACE [15]. 


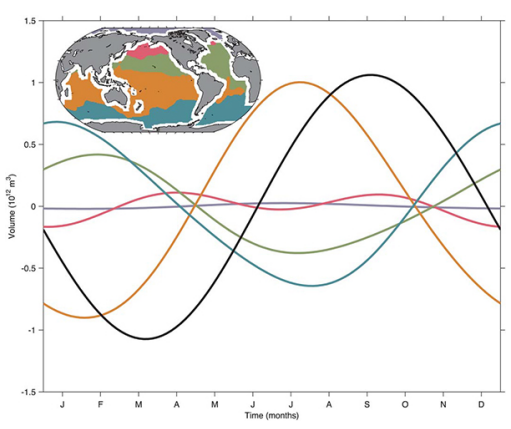

Figure 5: Seasonal mass redistribution among various areas with similar phases for monthly GRACE Release-05 $500 \mathrm{~km}$ smoothed maps. The seasonal cycles are shown here for the different latitude defined zones (inset map) with the black curve being the integrated Global curve [14].

\section{Earthquakes and Gravity}

Song and Simons [16] has reported that within the regions where one of the Earth's plates slips below another, areas where the attraction due to gravity is relatively high are less likely to experience large earthquakes than areas where the gravitational force is relatively low. The gravity potential signature of an earthquake at a location would be mainly associated with the vertical displacement of the Earth's surface between earthquake events. This vertical displacement triggers isostatic adjustment of the crust with the potential of inducing sea level change. Earthquakes are isolated single events information for which is available from USGS. Should it be possible for segregating the gravitational field variations due to mass changes owning to climatic factors, the remnant field could be attributed to vertical displacement resulting from earthquakes. De Viron et al. [17], provided insights into retrieving signature of gravity variations from GRACE from seismic events and concluded that the empirical orthogonal function (EOF) decomposition is key to separate the geopotential variations emanating from a seismic event. GRACE data can greatly help in understanding how earthquakes influence the earth's gravity field changes and this would help improve the sensitivity of predicting sea level changes, isostatic compensation and sub-crustal mass addition, thereby improving climate prediction models.

\section{Polar Wandering}

The slow erratic movement of the Earth's poles relative to the continents throughout geological time is known as polar wandering. This movement was considered to be very slow, largely due to drifting of the Earth's crustal plates. For the first time, Adhikari [18] demonstrated that the strong deviation in linear drift since 2000 was influenced by the decadal variability in global continent ocean mass transport, with changes in terrestrial water storage (TWS) playing a larger role as continental drift is insignificant in this period. Study of GRACE gravity based land and ocean mass movement patterns, it is now possible to forecast the direction of this polar tilts (Figure 6), thereby predicting changes in climate pattern shifts.

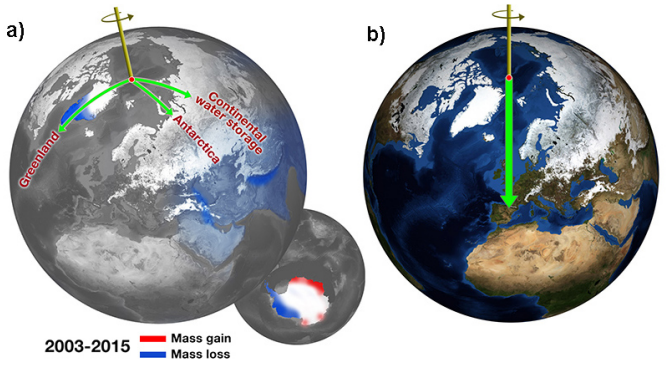

Figure 6: The vectors from land and ocean mass transfer between 2003 and 2015 (left) and the resultant vector indicating the direction of shift of the Earth's axis (right) Sourced from NASA/ JPL-Caltech.

\section{Future Needs}

The scientific goal of the GRACE satellite mission is to measure the gravitational field of the earth and its changes over time on a global scale with unprecedented accuracy. This has been achieved with significant concessions to spatial resolution and smoothed measurements which has triggered applications that address variations rather than absolute value of the gravity field. A global gravity map is completed approximately every 30 days and therefore the gravity field can be assumed as a monthly average of values [19-21]. This is better than all sources which were used before GRACE and also more accurate by a factor of 100 but at the same time limits the data to a monthly temporal resolution and also impacts the original values (since they are processed, aggregated and smoothed for a seamless monthly global dataset). Future satellite platforms need to address this issue of spatial resolution and sensor scale noise reduction.

Since GRACE does not measure gravity by direct means, this essentially means that the gravity calculations needs to be done, and validated before they are released for any meaningful interpretation. This introduces a latency of weeks for the gravity field data and more than a month for applications based products like the Land mass and Ocean mass products. Automated processing for reliable timely data product generation and validation are needed to support timely studies and for the information to be used for updating predictive models.

Another key challenge is that GRACE gravity is a sum of all contributing factors at an area and isolation of the factors resulting from each competent in this vertical column are based on sparse ground based sensors and observations. This induces reliability issues and uncertainty in the results and their interpretations.

The utility of GRACE, as discussed above, is therefore primarily aimed improving our understanding on the recent past environment and climate and on development of algorithms to isolate the various contributing components for the overall gravity field of an area.

\section{Conclusion}

The mass balance study of the continental water content, which is ultimately a sum of precipitation, evaporation, runoff and storage. Water is connected directly to weather and climate and with GRACE data its movement can be monitored on land and on oceans at a global 
scale. Season-dependent changes in the major river basins could therefore be studied coupled with anthropogenic use of surface water and ground water. Quantification of the increase or decrease of the ice and snow masses in the polar or large glacier areas from GRACE data have been well correlated with climatic phenomenon like shift in patterns of the rainfall patterns in West Antarctica and the reduction of ice mass there. GRACE also contributes to better understanding of global ocean circulation and heat transport from central latitudes to the Polar Regions though temporal observations of surface and deep currents. It was probably for the first time scientists were able to separate mass from ice melt or temperature from global warming to address sea level changes. Changes inside the solid earth and isostatic compensation of the region were also addressed using GRACE data through studying earthquake events since its launch.

GRACE gravity, through its continuous mapping of gravity variation, has largely improved our understanding on earth's surface processes and interactions between hydrosphere, lithosphere, cryosphere and biosphere and the impact of climate change to an extent where new requirements have emerged to define future mission to enhance the gravity signals for objective discourses. Future mission could incorporate the issue of latency, inherent harmonic noise and data resolution issues to advance the application of gravity variations for climate change studies and even into climate forecasting models.

\section{References}

1. Wouters B, Bonin JA, Chambers DP, Riva REM, Sasgen I, et al. (2014) GRACE, time-varying gravity, Earth system dynamics and climate change. Rep Prog Phys 77: 1-41.

2. Ray RD, Luthcke SB (2006) Tide model errors and GRACE gravimetry: towards a more realistic assessment. Geophys J Int 167: 1055-1059.

3. Schrama EJO, Visser PNAM (2007) Accuracy assessment of the monthly GRACE geoids based upon a simulation. J Geod 81: 67-80.

4. Rodell M, Houser PR, Jambor U, Gottschalck J, Mitchell K, et al. (2004) The Global Land Data Assimilation System. Bull Am Meteorol Soc 85: 381-894.

5. Watkins MM, Wiese DN, Yuan DN, Boening C, Landerer FW (2015) Improved methods for observing Earth's time variable mass distribution with GRACE using spherical cap mascons. J Geophys Res Solid Earth 120: 2648.

6. Famiglietti JS (2004) Remote sensing of terrestrial water storage, soil moisture and surface waters. American Geophysical Union 150: 197-207.

7. Ramillien G, Famiglietti JS, Wahr J (2008) Detection of Continental Hydrology and Glaciology Signals from GRACE: A Review. Surv Geophys 29: 361-374.
8. Hirschi M, Seneviratne SI, Schaer C (2006) Seasonal variations in terrestrial water storage for major midlatitude river basins. J Meteorol 7: 39-60.

9. Hall AC, Schumann GJ, Bamber JL, Bates PD (2011) Tracking water level changes of the Amazon Basin with space-borne remote sensing and integration with large scale hydrodynamic modelling: A review. Phys Chem Ear 36: 223-231.

10. Xiang L, Wang H, Steffen H, Wu P, Jia L, et al. (2016) Groundwater storage changes in the Tibetan Plateau and adjacent areas revealed from GRACE satellite gravity data. Earth Plane Sci Lett 449: 228-239.

11. Schmidt R, Petrovic S, Guntner A, Barthelmes F, Wunsch J, et al. (2008) Periodic components of water storage changes from GRACE and global hydrology models. J Geophys Res 113: B08419.

12. Cazenave A, Chen J (2010) Time-variable gravity from space and presentday mass redistribution in the Earth system. Earth Plan Sci Lett 298: 263-274.

13. Velicogna I, Wahr J (2013) Timevariable gravity observations of ice sheet mass balance: Precision and limitations of the GRACE satellite data. Geophys Res Lett 40: 3055-3063.

14. Johnson GC, Chambers DP (2013) Ocean bottom pressure seasonal cycles and decadal trends from GRACE Release05: Ocean circulation implications. J Geophys Res Oceans 118: 4228-4240.

15. Chambers DP, Bonin JA (2012) Evaluation of Release-05 GRACE timevariable gravity coefficients over the ocean. Ocean Sci 8: 859-868.

16. Song TA, Simons M (2003) Large Trench-Parallel Gravity Variations Predict Seismogenic Behavior in Subduction Zones. Science 301: 630-633.

17. De Viron O, Panet I, Mikhailov V, Van Camp M, Diament M (2008) Retrieving earthquake signature in grace gravity solutions. Geophys J Int 174: 14-20.

18. Adhikari I (2016) Climate-driven polar motion: 2003-2015, American Association for the Advancement of Science.

19. Karpik AP, Kanushin VF, Ganagina IG, Goldobin DN, Mazurova EM (2015) Analyzing spectral characteristics of the global Earth gravity field models obtained from the CHAMP, GRACE and GOCE space missions. Gyroscopy Navig 6: 101-108.

20. Luthcke SB, Zwally HJ, Abdalati W, Rowlands DD, Ray RD, et al. (2006) Recent Greenland ice mass loss by drainage system from satellite gravity observations. Science 314: 1286-1289.

21. Nerem RS, Jekeli C, Kaula WM (1995) Gravity field determination and characteristics: Retrospective and prospective. J Geophys Res 100: 15053-15074. 